\title{
Numerical Modeling of Reaction and Flow Characteristics in a Blast Furnace with Consideration of Layered Burden
}

\author{
Kwangheok YANG, ${ }^{1)}$ Sangmin $\mathrm{CHOI}^{1)}$ Jinkyung $\mathrm{CHUNG}^{2)}$ and Jun-ichiro YAGI ${ }^{3)}$ \\ 1) Department of Mechanical Engineering, Korea Advanced Institute of Science and Technology, Daejeon, 305-701 Korea. \\ E-mail: smchoi@kaist.ac.kr $\quad$ 2) Technical Research Laboratories, POSCO, Gwangyang, 545-711 Korea. 3) Tohoku \\ University, Sendai, Miyagi 980-8577 Japan.
}

(Received on November 2, 2009; accepted on January 18, 2010)

\begin{abstract}
A blast furnace is modeled as a counter-current bed reactor filled with solid particles of coke and ore where the gas flows upward through the porous media while the bed material moves slowly in the countercurrent direction of the gas flow. An axi-symmetric two-dimensional steady state model is proposed to simulate the gas and the solid flow, where thermo-chemical reactions and heat transfer process are considered. It is assumed that two phases of solid and gas exist in the furnace. The charged material is treated as porous media constructed by alternative coke and ore layers, which have different permeability. The internal gas flow of the furnace is governed principally by burden distribution. For understanding of the influence of the burden distribution on the internal situation, the entire layer structure is predicted from the measured top layer structure and the solid flow is assumed as the potential flow. Using this burden distribution, the flow, energy, and chemical species conservation equations are derived for each phase. In addition, the phase mass generation/consumption caused by reactions, heat transfer between gas and solid phases, and the reaction heat are reflected in source terms in the governing equations. For several different $L_{o} / L_{c}$ (layer thickness ratio of ore and coke layer) cases, layer structures are constructed and numerical simulations are conducted. The finite volume method was used for the numerical simulations. Through this approach, the flow, composition and temperature distributions within the furnace are numerically predicted.
\end{abstract}

KEY WORDS: blast furnace; burden distribution; numerical model; chemical reaction; heat transfer.

\section{Introduction}

In the blast furnace, coke, ore, and flux are charged into the top of the furnace and hot air $\left(\sim 1100^{\circ} \mathrm{C}\right)$, enriched oxygen, and hydrocarbon additives are blasted through the tuyeres. Hot blast gas which contains reducing gases such as $\mathrm{CO}$ and $\mathrm{H}_{2}$, generated as a result of combustion in the raceway, heats up the charged material during flowing up through packed bed. Iron ore is reduced and melt by the reducing gases. Molten pig iron and slag are discharged through the tap hole near the bottom of the furnace, and off gases exit from the top of the furnace.

Recently, quality of ore and coal in iron-making processes has been deteriorated because of the high economics and low availability related with the resource shortage. Additionally, environmental concern including the carbon dioxide emission has become an important issue, and operating conditions in the blast furnace have been affected to response such social requirements resulting in more difficulties to maintain operational stability. In order to improve these situations it is useful to develop a simulation model for predicting the in-furnace situation and operation results of the blast furnace.

Over the past few decades a considerable number of studies have been made on mathematical models of the blast furnace. Several continuum models developed in 2 or
3 dimension have been applied to improve practical operations. Yagi et al. derived a two-dimensional steady state model considering four phases such as lump solid, gas, liquid, and fines, ${ }^{1-3)}$ and the computational domain was extended later to three-dimension. ${ }^{4)}$ Sugiyama and Sugata developed the BRIGHT model which includes charging distribution model and forecasts distribution of the burden as well as temperature distribution of burden and chemical composition at the top. ${ }^{5)}$ Recently, a three dimensional unsteady state model has been also developed by Takatani et al., ") which simulated dynamic behavior of blast furnace, such as blow-in and blow-off operation. General trend of model development has been directed to incorporate more complex geometry and more detailed behaviors in the processes.

Coke and ore are charged alternately at the top of the furnace. Layer structure of coke and ore controlled by rotating angle and velocity of the chute is one of main operational factors, which determines principally permeability distribution in the blast furnace with Bell-less charging devices. However, most of previous studies of numerical simulation $^{1-6)}$ have assumed charging material as mixed layer of coke and ore. Influence of the burden distribution on the in-furnace conditions has not been sufficiently investigated. The objective of this study was to develop a two dimensional model which can reflect the burden distribution and 
chemical reactions on the operation results. Simulation results are compared with the results of measurement data of an actual furnace for the verification of the model developed in this study.

\section{Computational Model}

Description of physical processes of flow, heat transfer, and mass conservation with chemical reactions inevitably requires simplification. First simplification is related with the dimension. Although the blast furnace has 3-dimensional characteristics in nature, 2-dimensional axi-symmetry will be assumed for simplicity while not sacrificing the significance of the in-furnace phenomena. Also, variation with lapse of time is not intended to analyze, so that only the steady-state modeling is conducted. In the modeling of this study, the blast furnace process is considered as a packed bed of solid particles and each particle has homogeneous composition. This would enable to consider the packed bed as a continuum, so that discretization is possible.

Figure 1 shows the concept of the blast furnace modeling in this study. Layer structure should be calculated in order to reflect charging mode from the top. However, it is difficult to calculate layer structure and chemical reaction simultaneously, because layer structure is affected by mass loss due to chemical reaction. Therefore, at first we obtain a layer structure without chemical reaction, while mass generation or consumption by chemical reactions is not considered in this step. This layer structure is then, used for considering the chemical reactions and energy conservation. Blast furnace geometry, coke base line, $L_{\mathrm{o}} / L_{\mathrm{c}}$ distribution, thickness of coke and ore layer and height of deadman could be changed in the input condition. Calculation domain for solving the solid velocity is the upper part of the deadman and the raceway because the deadman is assumed for particles not to enter.

\subsection{Burden Structure Prediction Model}

Coke and ore charged into the blast furnace form alternating layers. Top burden profile is obtained from the distance data between the stock-line and the surface of the charged material, measured by a microwave profile-meter at
100 points in radial direction. Layer structure measured after one charging cycle is presented in Fig. 2(a). One charging cycle consists of 5 layers according to the kind of burden material and particle size. Center coke is the coke charged into the center region to obtain preferential gas flow there. While, small ore particles are charged near the wall, which would increase the resistance to the gas flow.

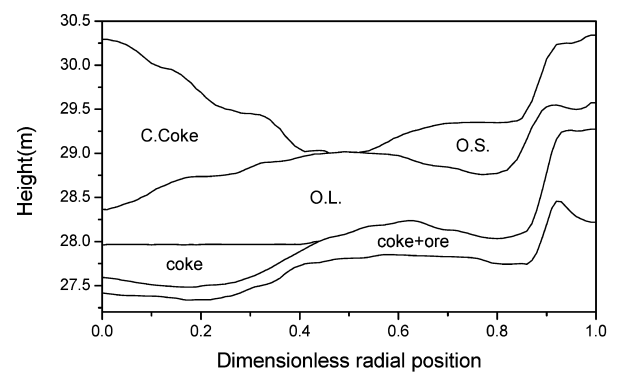

(a)

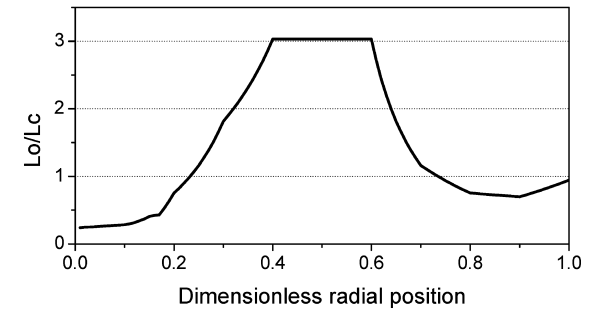

(b)

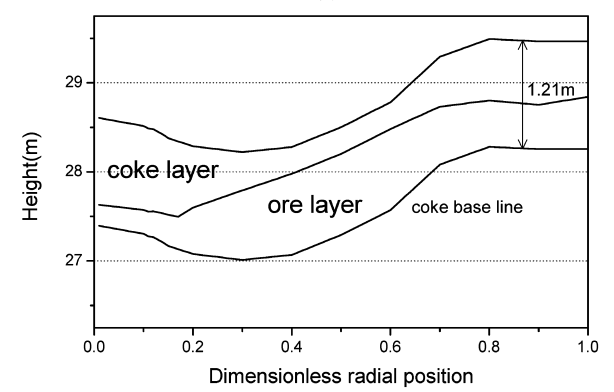

(c)

Fig. 2. (a) Top burden layer profile in an actual operation of blast furnace: O.S., small ore particle $\left(d_{p}=10 \mathrm{~mm}\right)$; O.L., large ore particle $\left(d_{p}=20 \mathrm{~mm}\right)$; Coke + Ore, mixture of coke and ore; C. Coke, center coke. (b) A typical $L_{\mathrm{o}} / L_{\mathrm{c}}$ distribution at the furnace top, and (c) reconstructed top burden structure model.

Burden structure prediction model

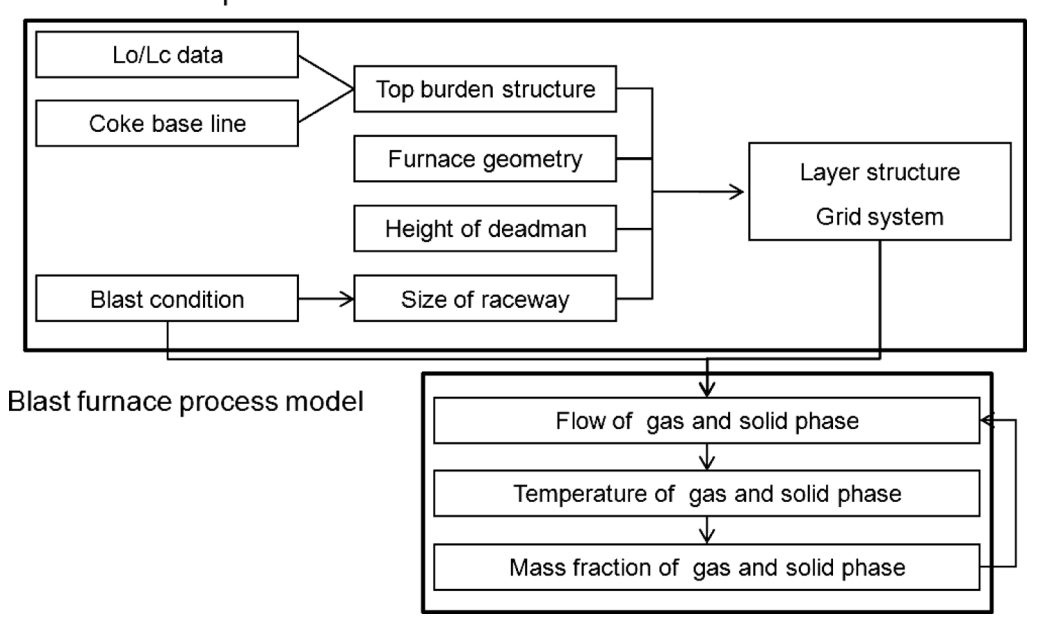

Fig. 1. Concept of blast furnace modelling. 
In this study, the complex layer structure in a practical blast furnace operation is represented by only two burden layers of coke and ore. Figure 2(b) shows obtained $L_{\mathrm{o}} / L_{\mathrm{c}}$, which means the ratio of layer thickness of ore and coke, data measured in Pohang BF\#3 in POSCO. At the central region, $L_{\mathrm{o}} / L_{\mathrm{c}}$ has small value because coke is heavily charged into central core region, and $L_{\mathrm{o}} / L_{\mathrm{c}}$ increases along the radial direction and reaches the maximum value at $r / R=0.4-0.6$. Using this data, a pair of ore and coke layers is constructed as in Fig. 2(c). Thickness of coke and ore layers is $1.21 \mathrm{~m}$. Coke base surface is determined according to a measured burden profile.

Several assumptions are necessary to obtain whole layer structures for the remaining region from the information on the top burden structure. Solid particles are assumed to be homogeneous and to move as a continuum, i.e. crush and rolling of solid particles are not considered, and layers of coke and ore move smoothly downward and eventually all solid materials are assumed to be discharged through the raceway. Therefore, burden distribution in the whole furnace is obtained from the top burden profile and solid velocity. In this study, solid flow is assumed to follow potential flow, where the solid velocity is represented as a gradient of a stream function $\psi$

$$
\vec{G} s=-\nabla \psi
$$

Despite its simplicity, potential flow is known to predict the flow of solid in the shaft part with reasonable confidence. ${ }^{7)}$ First, solid velocity is calculated in the arbitrary grid system. Then new grid system could be constructed by streamline as shown in Fig. 3(a). Because solid particles move down along the streamline, time interval between two points is calculated by dividing the distance by the velocity at the point on the streamline, as represented in Eq. (2).

$$
\Delta t=\frac{\overline{A B}}{v}
$$

At the top of the burden surface, time is set to be 0 . Then, time is obtained at each point by sequentially adding along the streamline. Consequently, layer structure could be obtained by combining timeline and top burden structure as shown in Fig. 3(b). Period of one charging of coke and ore is defined as $T$. After one time interval of $T$, each layer moves down and thereby forms the next layer. This process is repeated until the layer of the solid particle reaches the exit, i.e. the raceway.

\subsection{Blast Furnace Process Modeling}

Gas flow in the packed bed and interaction of gas with solid particles are the principal part of the blast furnace process modeling. Approach for the flow through packed beds will be adopted. Conservation of heat and mass for gas phase must be satisfied while the composition of the gas phase may change due to chemical reactions. Chemical composition in the solid iron ore changes from $\mathrm{Fe}_{2} \mathrm{O}_{3}$ to $\mathrm{Fe}$ through intermediate oxides of $\mathrm{Fe}_{3} \mathrm{O}_{4}, \mathrm{Fe}_{w} \mathrm{O}$, where $w$ is the atomic ratio of iron to oxygen in wustite, which varies from 0.95 at the wustite-iron boundary to 0.85 at the wustitemagnetite boundary in atmospheric pressure. ${ }^{8)}$ However, $w$ is set as 0.947 in this study. Gas phase is assumed to

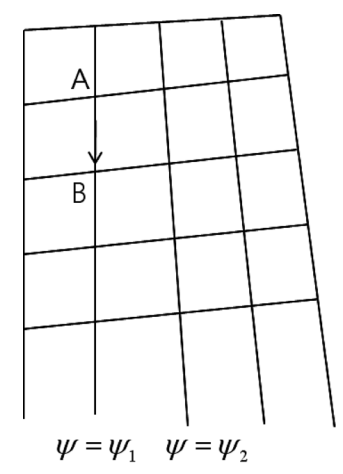

(a)

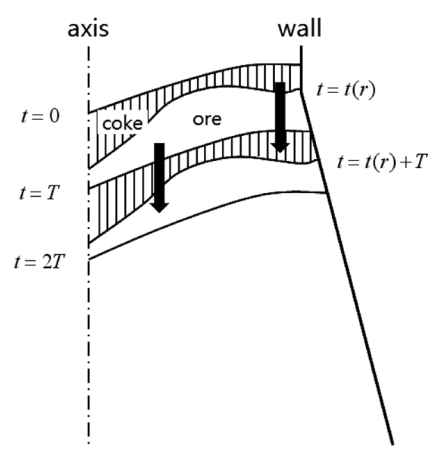

(b)
Fig. 3. Concept of burden structure prediction model: (a) timeline by velocity and streamline, and (b) layer structure by combining timeline and top burden structure.

include $\mathrm{CO}, \mathrm{CO}_{2}, \mathrm{H}_{2}, \mathrm{H}_{2} \mathrm{O}$ and $\mathrm{N}_{2}$.

Layer structure of coke and ore is calculated beforehand as described in the previous section of the burden structure prediction model. Coke and ore diameters are assumed to be given respectively as fixed values and not to be changed by chemical reactions. Shape of the raceway is assumed as a two dimensional rectangle. Analysis of raceway phenomena is not included in the present model. Adiabatic flame temperature and gas compositions, calculated by heat and mass balance, are applied as boundary conditions at the raceway. ${ }^{9)}$ The cohesive zone was defined as a region of solid temperature ranging from 1050 to $1350^{\circ} \mathrm{C}$. The decreased permeability in the cohesive zone is expressed by the change of the void fraction. Deadman is assumed to have a bell-like shape, which is represented by a quadratic equation. ${ }^{1)}$

\subsubsection{Governing Equations}

A generalized transport equation for the mass, momentum, energy and chemical species is shown below

$$
\nabla \cdot(\vec{G} \phi)=\nabla \cdot(\Gamma \nabla \phi)+S_{\phi}
$$

Where, $\phi, G, \Gamma, S_{\phi}$ represents general dependent variables to be solved, mass velocity, diffusion coefficient and the source term. Detailed governing equations for each phase are presented in Table 1. Mass, energy and species conservation equations can be written from the equation. Source term of each conservation equation is closely combined through the interaction such as heat and mass transfer between phases. Ergun's equation is applied to describe the gas flow and solid velocity is assumed to be proportional to the gradient of the velocity potential. In the energy conservation equation, conduction, convection, heat exchange between the gas and the solid phases and reaction heat are considered in the model. $\alpha$ in the energy conservation equation means fraction of reaction heat absorbed by the solid phase.

Heat transfer coefficient between the gas and the solid can be calculated using the Ranz-Marshall equation, ${ }^{10)}$ as described below:

$$
h_{g s}=\frac{k_{g}}{d_{p}}\left(2.0+0.6 \operatorname{Re}_{g s}^{1 / 2} \operatorname{Pr}_{g}^{1 / 3}\right)
$$


ISIJ International, Vol. 50 (2010), No. 7

Table 1. Governing equations for each phase.

\begin{tabular}{|c|c|c|}
\hline & Solid & Gas \\
\hline Mass & $\nabla \cdot \vec{G}_{s \rightarrow g}=-\dot{m}_{s \rightarrow g}-\dot{m}_{m e l t}$ & $\nabla \cdot \vec{G}_{g}=\dot{m}_{s \rightarrow g}$ \\
\hline Flow & $\vec{G}_{s}=-\nabla \psi$ & $\begin{array}{l}-\nabla P=\left(f_{1}+f_{2}\left|\vec{G}_{g}\right|\right) \vec{G}_{g}, \quad \text { where, } \\
f_{1}=150 \frac{\left(1-\varepsilon_{i}\right)^{2} \mu}{\left(\phi_{i} d_{p i}\right) 2 \varepsilon_{i}^{3} \rho_{g}}, \quad f_{2}=1.75 \frac{\left(1-\varepsilon_{i}\right)}{\phi_{i} d_{p i} \varepsilon_{i}^{3} \rho_{g}} \\
\mathrm{i}=\text { coke or ore }\end{array}$ \\
\hline Energy & $\begin{array}{l}\nabla \cdot\left(\vec{G}_{s} C_{p} T_{s}-(1-\varepsilon) k_{s} \nabla T_{s}\right) \\
\quad=h_{g s} A_{g s}\left(T_{g}-T_{s}\right)-\alpha \sum_{k=1}^{N} R_{k}\left(-\Delta H_{k}\right)\end{array}$ & $\begin{array}{l}\nabla \cdot\left(\vec{G}_{g} C_{p} T_{g}-\varepsilon k_{g} \nabla T_{g}\right) \\
\quad=h_{g s} A_{g s}\left(T_{s}-T_{g}\right)-(1-\alpha) \sum_{k=1}^{N} R_{k}^{\text {react }}\left(-\Delta H_{k}\right)\end{array}$ \\
\hline $\begin{array}{l}\text { Chemical } \\
\text { Species }\end{array}$ & $\begin{array}{l}\nabla \cdot\left(\vec{G}_{s} \omega_{s, i}\right)=\sum_{k=1}^{N} S_{\omega_{t, t}}^{\text {raact }} \\
\text { where, } i=\mathrm{Fe}_{2} \mathrm{O}_{3}, \mathrm{Fe}_{3} \mathrm{O}_{4}, \mathrm{Fe}_{w} \mathrm{O}, \mathrm{Fe} \text {, gangue, } \mathrm{C} \text { and ash }\end{array}$ & $\begin{array}{l}\nabla\left(G_{g} \omega_{g, i}\right)=\sum_{k=1}^{N-\text { react }} S_{\omega_{g, j, k}} \\
\text { where, } i=\mathrm{O}_{2}, \mathrm{CO}, \mathrm{CO}_{2}, \mathrm{H}_{2}, \mathrm{H}_{2} \mathrm{O} \text { and } \mathrm{N}_{2}\end{array}$ \\
\hline
\end{tabular}

Surface area can be expressed as:

$$
A_{g s}=\frac{6(1-\varepsilon)}{d_{p} \phi}
$$

\subsubsection{Chemical Reactions}

Table 2 shows chemical reactions considered in this study. Indirect reduction by $\mathrm{CO}$ gas $(k=1,2,3)$, indirect reduction by $\mathrm{H}_{2}$ gas $(k=4,5,6)$, solution loss $(k=7)$, melting of iron ore $(k=8,9)$ and direct reduction $(k=10)$ are considered. The indirect reduction rates are obtained by using 3-interface shrinking core model ${ }^{11,12)}$ and solutionloss rate is determined by the reaction kinetics and diffusion. ${ }^{13)}$

Heat of reaction is calculated by difference of enthalpy of formation between reactants and products as described in Eq. (6)

$$
\Delta H=H_{\text {product }}-H_{\text {reactant }}=\sum_{i=1}^{N} v_{i}^{\prime \prime} H_{f, M_{i}}^{\circ}-\sum_{i=1}^{N} v_{i}^{\prime} H_{f, M_{i}}^{\circ}
$$

\subsubsection{Physical Properties}

Density of gas is calculated by ideal gas equation. Density of coke and ore, specific heat and thermal conductivity of each component were taken from the literature. ${ }^{14)}$ Chapman-Enskog theory was used to obtain gas diffusivity. ${ }^{15)}$

\section{Computational Strategy}

\subsection{Solver}

The governing equations are solved by a generalized partial differential equation solver which was written based on the finite volume method. In the discretization of the differential equation set, various methods are available for each phase, such as central, upwind, hybrid and power-law methods. The under-relaxation of the primary variables was performed in the iterative solution, to handle the strong heat and mass interaction between the solid and gas phases. Tridiagonal matrix algorithm (TDMA) is adopted for solving discretized equations. ${ }^{16)}$ The solution procedure is shown in Fig. 4. Velocity, energy and mass fraction equations are solved for each phase and whole iteration calculations are repeated until results are converged. Computer code is programmed by $\mathrm{C}^{++}$. Non-rectangular grid is adopted so that grid is constructed according to the layer structure. Detailed procedure of discretization method for non-orthogonal
Table 2. Chemical reactions.

\begin{tabular}{|c|l|l|}
\hline $\begin{array}{l}\text { Reaction } \\
\text { Number(k) }\end{array}$ & Reactions & $\begin{array}{c}\text { Reaction } \\
\text { Rate }\end{array}$ \\
\hline 1 & $3 \mathrm{Fe}_{2} \mathrm{O}_{3}(s)+\mathrm{CO} \rightarrow 2 \mathrm{Fe}_{3} \mathrm{O}_{4}(s)+\mathrm{CO}_{2}(g)$ & {$[11-12]$} \\
\hline 2 & $\frac{w}{4 w-3} \mathrm{Fe}_{3} \mathrm{O}_{4}(s)+\mathrm{CO}(g) \rightarrow \frac{3}{4 w-3} \mathrm{Fe}_{w} O(s)+\mathrm{CO}_{2}(g)$ & {$[11-12]$} \\
\hline 3 & $\mathrm{Fe}_{w} \mathrm{O}(s)+\mathrm{CO}(g) \rightarrow w F e(s)+\mathrm{CO}_{2}(g)$ & {$[11-12]$} \\
\hline 4 & $3 \mathrm{Fe}_{2} \mathrm{O}_{3}(s)+\mathrm{H}_{2}(g) \rightarrow 2 \mathrm{Fe}_{3} \mathrm{O}_{4}(s)+\mathrm{H}_{2} \mathrm{O}(g)$ & {$[11-12]$} \\
\hline 5 & $\frac{w}{4 w-3} \mathrm{Fe}_{3} \mathrm{O}_{4}(s)+\mathrm{H}_{2}(g) \rightarrow \frac{3}{4 w-3} \mathrm{Fe}_{w} \mathrm{O}(s)+\mathrm{H}_{2} \mathrm{O}(g)$ & {$[11-12]$} \\
\hline 6 & $\mathrm{Fe}_{w} \mathrm{O}(s)+\mathrm{H}_{2}(g) \rightarrow w F e(s)+\mathrm{H}_{2} \mathrm{O}(g)$ & {$[11-12]$} \\
\hline 7 & $\mathrm{C}(s)+\mathrm{CO}_{2}(g) \rightarrow 2 \mathrm{CO}(g)$ & {$[13]$} \\
\hline 8 & $\mathrm{Fe} e_{w} \mathrm{O}(s) \rightarrow \mathrm{Fe} e_{w} \mathrm{O}(l)$ & {$[2]$} \\
\hline 9 & $\mathrm{Fe}(s) \rightarrow \mathrm{Fe}(l)$ & {$[2]$} \\
\hline 10 & $\mathrm{Fe} e_{w} O(l)+\mathrm{C}(s) \rightarrow w F e(l)+\mathrm{CO}(g)$ & {$[2]$} \\
\hline
\end{tabular}

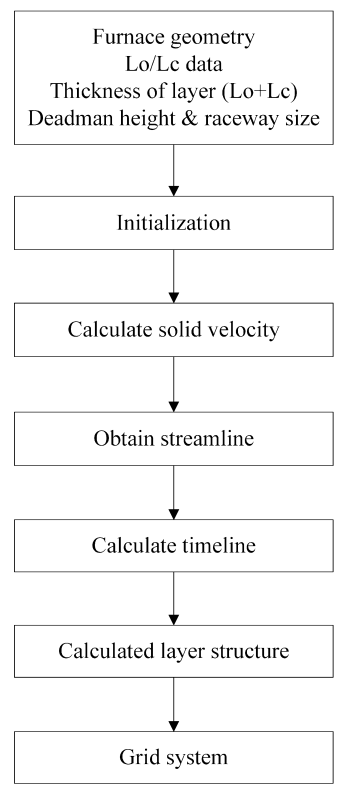

(a)

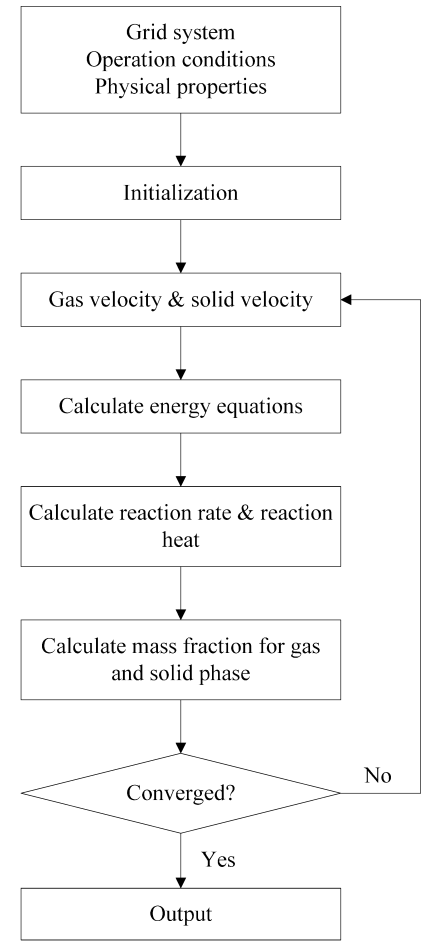

(b)
Fig. 4. Solution procedure for (a) burden structure prediction model and (b) blast furnace process model.

grids is referred from Ref. 17).

To derive the discretized equation, interface diffusion coefficient should be evaluated. Coke and ore layers are piled up by turns. Therefore, harmonic mean of $\Gamma_{P}$ and $\Gamma_{N}$ is 


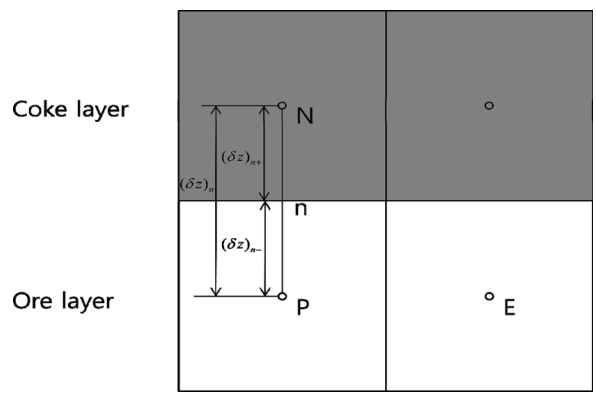

Fig. 5. Distances associated with the interface $n$.

used at the interface $n$ due to the nonhomogeneity of material as shown in Eq. (7) ${ }^{16)}$.

$$
\Gamma_{n}=\frac{\Gamma_{P} \Gamma_{N}}{f_{n} \Gamma_{P}+\left(1-f_{n}\right) \Gamma_{N}}
$$

Where, interpolation factor $f_{n}$ is a ratio defined in terms of the distances shown in Fig. 5:

$$
f_{n} \equiv \frac{(\delta z)_{n+}}{(\delta z)_{n}}
$$

\subsection{Boundary Conditions}

Figure 6 shows the boundary conditions in this model. Boundary conditions of the raceway are applied for all the governing equations except the gas flow. All oxygen and hydrogen, included in air, enriched oxygen and moisture, react with carbon and are changed into $\mathrm{CO}$ and $\mathrm{H}_{2}$ respectively. The temperature of coke flowing into the raceway is assumed to be $1527^{\circ} \mathrm{C}$. Assuming the conservation of enthalpy, adiabatic temperature is calculated from a simple heat balance. This temperature is adopted as the gas temperature at the boundary of the raceway. For gas flow, mass velocity of the gas is given as boundary condition as an inlet condition and top pressure is used as an exit condition. Temperature of the gas and the solid at the inlet is given as fixed values at raceway boundary and at furnace top respectively. Heat flux by diffusion at the outlet is set as zero. Heat loss due to the cooling stave of the wall is considered. $T_{\mathrm{w}}$ is wall temperature and $T_{\infty}$ is ambient temperature in Fig. 6. In this study $U$ and $T_{\infty}$ are given, and $T_{w}$ is calculated from the boundary condition, and $T_{\infty}$ is set to $27^{\circ} \mathrm{C}$. On the central axis, the gradients of all dependent variables are equal to zero following the axi-symmetric condition.

\section{Results and Discussions}

\subsection{Calculation Case}

The process analyzed in this study is Pohang BF\#3, which has working volume, $4350 \mathrm{Nm}^{3}$, effective height of the furnace, $24.87 \mathrm{~m}$, radius of the hearth, $6.95 \mathrm{~m}$, height of the bosh, $4.8 \mathrm{~m}$ and radius of the belly, $7.95 \mathrm{~m}$. Table 3 shows operating conditions of the blast furnace. Productivity of this blast furnace is about 13000 ton/d. Preheated air and enriched oxygen are blasted through the tuyere. In addition, pulverized coal also injected through the tuyere as auxiliary reducing agent. Ore and coke are charged from the top of the furnace.

Table 4 shows input parameters for calculation such as

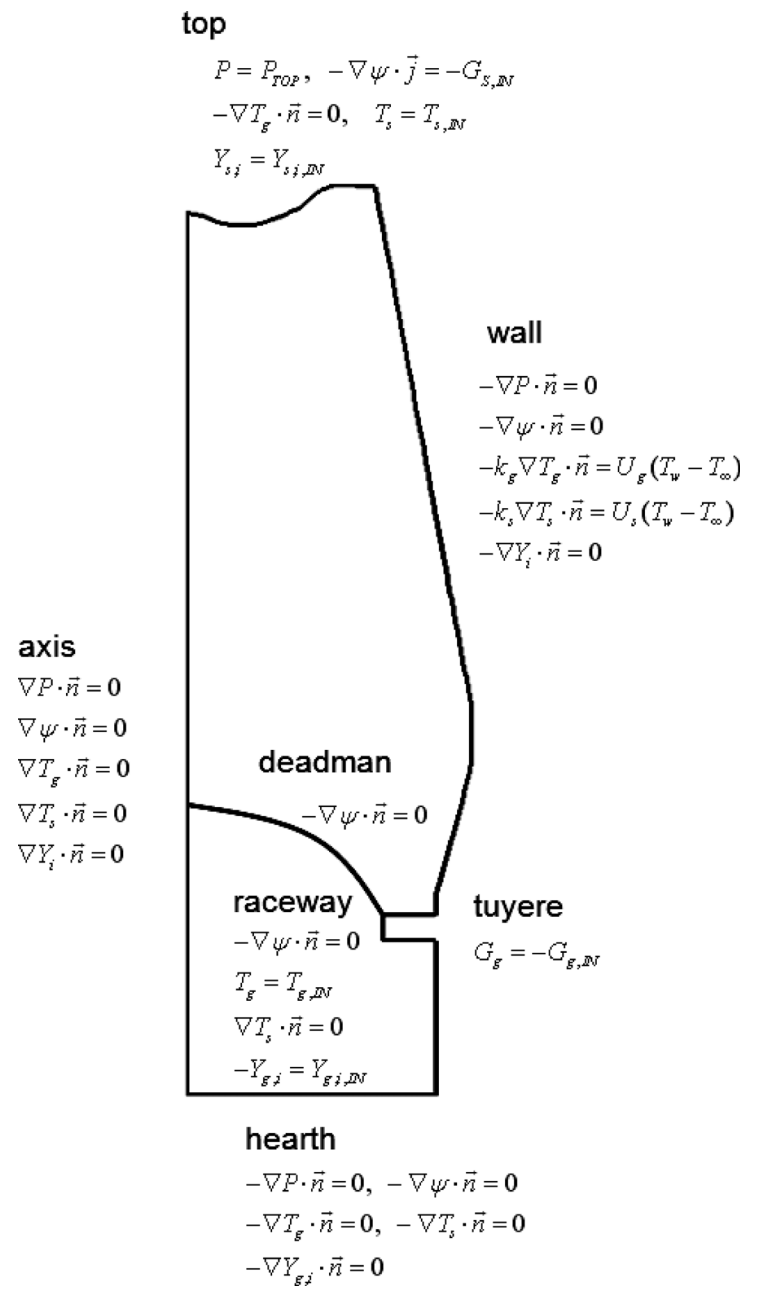

Fig. 6. Boundary conditions.

Table 3. Operation conditions.

\begin{tabular}{|l|r|}
\hline Top gas pressure $(\mathrm{MPa})$ & 0.277 \\
Blast volume $\left(\mathrm{Nm}^{3} / \mathrm{min}\right)$ & 6200 \\
Blast temperature $\left({ }^{\circ} \mathrm{C}\right)$ & 1196 \\
Production rate of pig iron $(\mathrm{t} / \mathrm{d})$ & 13271 \\
$\mathrm{PCR}(\mathrm{kg} / \mathrm{t}-\mathrm{pig})$ & 180 \\
$\mathrm{O}_{2}$ rate $\left(\mathrm{Nm}^{3} / \mathrm{hr}\right)$ & 51000.0 \\
$\mathrm{Blast}$ moisture $\left(\mathrm{g} / \mathrm{Nm}^{3}\right)$ & 30.1 \\
Coke rate $(\mathrm{kg} / \mathrm{t}$-pig) & 302 \\
Ore rate $(\mathrm{kg} / \mathrm{t}$-pig $)$ & 1600 \\
\hline
\end{tabular}

\begin{tabular}{|c|c|c|}
\hline \multicolumn{3}{|l|}{ Species } \\
\hline \multirow[t]{4}{*}{ Solid } & Iron & $80.7 \% \mathrm{Fe}_{2} \mathrm{O}_{3}, 19.3 \%$ gangue \\
\hline & Coke & $88 \% \mathrm{C}, 12 \%$ ash \\
\hline & $\mathrm{PC}$ & $79 \% \mathrm{C}, 5 \% \mathrm{H}, 6.8 \% \mathrm{O}, 1.5 \% \mathrm{~N}, 0.5 \% \mathrm{~S}, 7.2 \%$ ash \\
\hline & Ash, gangue & $34 \% \mathrm{SiO}_{2}, 35 \% \mathrm{CaO}, 22 \% \mathrm{Al}_{2} \mathrm{O}_{3}, 9 \% \mathrm{MgO}$ \\
\hline Gas & & $\mathrm{N}_{2}, \mathrm{O}_{2}, \mathrm{CO}, \mathrm{CO}_{2}, \mathrm{H}_{2}, \mathrm{H}_{2} \mathrm{O}$ \\
\hline \multicolumn{3}{|c|}{ Layer properties } \\
\hline Coke & \multicolumn{2}{|c|}{$\begin{array}{l}\mathrm{d}_{\mathrm{p}}=50 \mathrm{~mm} \text { (stack zone), } 25 \mathrm{~mm} \text { (dripping zone, deadman, and } \\
\text { raceway), } \phi=0.90, \varepsilon=0.43,0.20 \text { (deadman), } 0.80 \text { (raceway) }\end{array}$} \\
\hline Ore & \multicolumn{2}{|c|}{$\begin{array}{l}\mathrm{d}_{\mathrm{p}}=19.1 \mathrm{~mm}, 15.0 \mathrm{~mm}(\mathrm{r} / \mathrm{R}>0.75) \phi=0.84, \varepsilon=0.36,0.10(\text { cohesive } \\
\text { Zone) }\end{array}$} \\
\hline \multicolumn{3}{|c|}{ Boundary of raceway } \\
\hline \multicolumn{3}{|c|}{$\mathrm{T}_{\mathrm{F}}=2410.6 \mathrm{~K}, \mathrm{X}_{\mathrm{CO}}=0.429, \mathrm{X}_{\mathrm{H} 2}=0.109, \mathrm{X}_{\mathrm{N} 2}=0.462$} \\
\hline
\end{tabular}

Table 4. Input parameters for calculation.

the composition of each phase, layer properties, and boundary condition in the raceway for gas phase. Composition of ash and gangue is assumed to be same with composition of slag. Layer properties consist of particle diameter $\left(d_{p}\right)$, shape factor $(\phi)$ and porosity $(\varepsilon)$. Initial diameter of coke and ore charged into the top of furnace, is $50 \mathrm{~mm}$ and 
$19.1 \mathrm{~mm}$, respectively. As coke goes down, diameter of coke decreases due to solution-loss reaction. Therefore, diameter of the coke below the cohesive zone is set as $25 \mathrm{~mm}$, which is half of the initial diameter, and based on a measurement data of coke diameter distribution in Gwangyang BF\#1 in POSCO ${ }^{18)}$ Porosity of cohesive zone is set as 0.10 to reflect the low permeability due to melting and agglomeration. Porosity is increased to 0.80 in the raceway. In the practical operation of the blast furnace, gas permeability near the wall is lowered, because particle diameter of ore is smaller than that in other radial positions as seen in Fig. 2(a). Therefore, diameter of ore is set as $15 \mathrm{~mm}$ in the peripheral region $(r / R>0.75)$.

\subsection{Results and Discussion}

\subsubsection{Burden Structure Prediction Model}

Figure 7(a) shows calculated solid velocity contour and streamlines, and Fig. 7(b) shows timelines. A simulation result for layer structures and grid system are shown in Fig. 8. Black part of Fig. 8(a) indicates coke layer and gray part indicates ore layer. Layer structure is not calculated until the layers reach the raceway due to difficulty in calculation. If potential flow equation is combined with mass conservation equation, governing equation becomes a set of elliptic partial differential equations (PDE). Therefore, solid velocity is affected not only by the inlet condition but also by the shape of raceway. In this study shape of raceway is simplified as a rectangle. This potential flow assumption would not be adequate in the region close to the deadman and the raceway. If position of the cohesive zone calculated is higher than that of the layer constructed beforehand, the burden structure obtained would be accepted because no ore layer could be allowed below the cohesive zone. Once the burden structure is determined, a grid system for the subsequent numerical computation is constructed. Computational domain covers not only the stack zone but also the lower furnace region of dripping zone, deadman, and raceway. Number of computational cells is 25 in radial direction and is the same as layer number which is variable according to the layer thickness in axial direction.

\subsubsection{Blast Furnace Process Modeling}

Temperature and flow of each phase are calculated using the newly constructed grid system as shown in Figs. 9 to 11. The temperature distribution within the furnace is greatly affected by the layer structure. Charged materials are stacked at the top of the burden bed at $27^{\circ} \mathrm{C}$ and allowed to flow down along with increasing temperature due to heat transfer from the rising reducing gas. Coke temperature reaches about $2000^{\circ} \mathrm{C}$ when it comes to raceway region. It has been observed in the practical operation of the blast furnaces that temperature in the central and the peripheral regions is higher than that of the middle region. Relative volume of coke layer is not uniform in the radial direction, as presented in $L_{\mathrm{o}} / L_{\mathrm{c}}$ data and burden distribution in the Fig. 2(b). Because diameter of coke is larger than that of ore, permeability of coke layer is larger than that of ore layer, gas tends to flow through the region where more coke is charged. As the results, more gas will flow through the region where $L_{\mathrm{o}} / L_{\mathrm{c}}$ has a small value. For this reason, temperature in the central regions is higher than that of middle

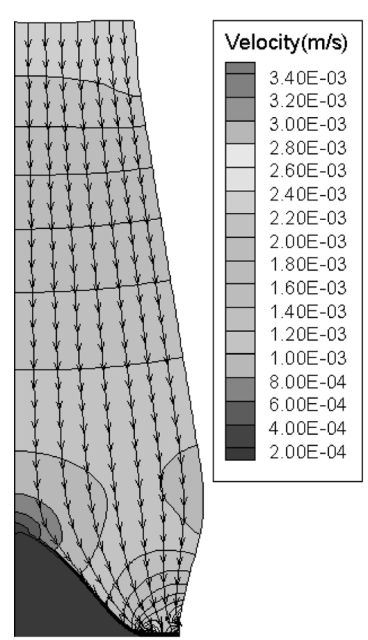

(a)

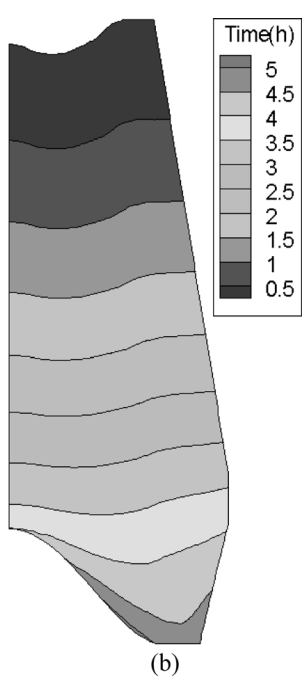

(b)
Fig. 7. Calculated (a) solid velocity contour and streamlines and (b) timelines.

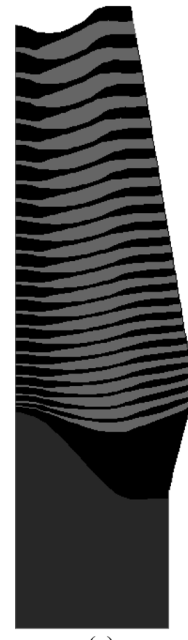

(a)

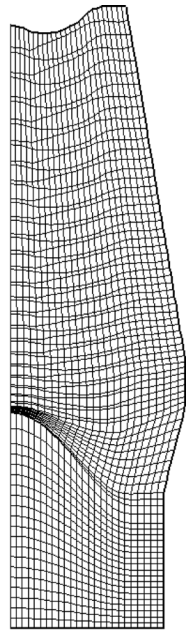

(b)
Fig. 8. Calculated (a) burden structure and (b) grid system.

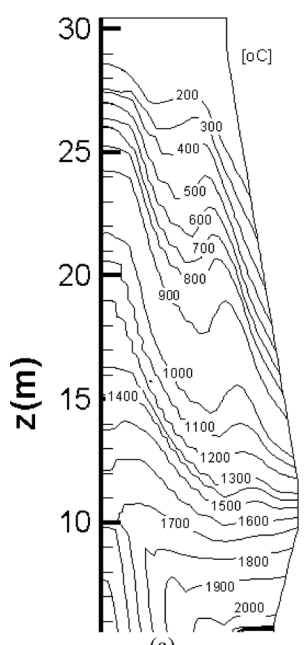

(a)

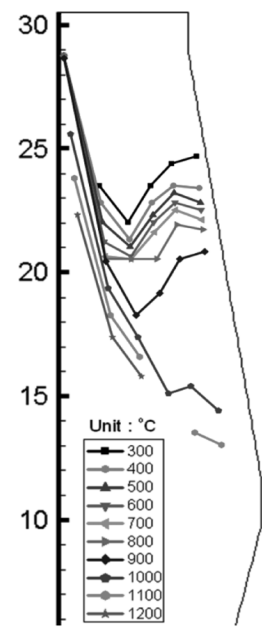

(b)
Fig. 9. Solid temperature distribution: (a) calculated data and (b) measured data.

region. Position of the cohesive zone $\left(T_{\mathrm{s}}=1050-1350^{\circ} \mathrm{C}\right)$ is located at $6-7 \mathrm{~m}$ above the tuyere level in the peripheral region. To prove the validity of the model developed here, 


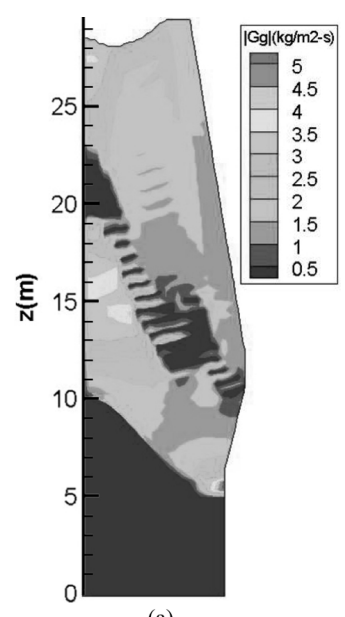

(a)

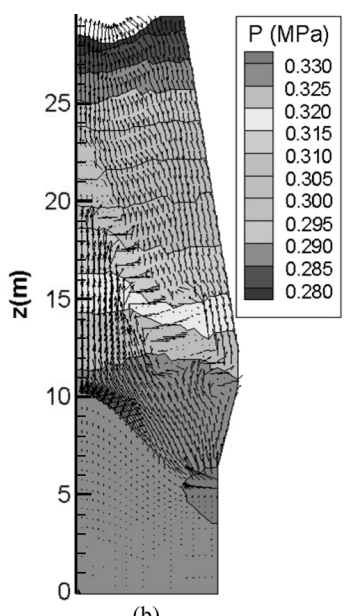

(b)

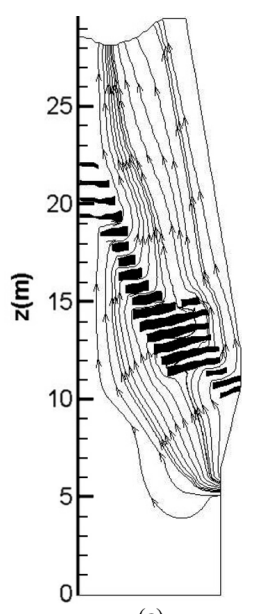

(c)

Fig. 10. Calculation results of gas flow: (a) contour of gas mass velocity $\left(\mathrm{kg} / \mathrm{m}^{2} \cdot \mathrm{s}\right)$, (b) velocity vector of gas and gas pressure distribution and (c) gas streamline through the coke slit.

the calculated temperature distribution is compared to the measured temperatures at 6 points by a vertical probe as shown in Fig. 9(b). The shape of the measured temperature distribution shows the $N$ type especially at low temperature region. On the other hand, $L$ type temperature distribution is shown in the high temperature region. There are noticeable discrepancies between the temperature of calculation and that of measurement at periphery. Measured temperatures are higher than calculated ones at periphery. These discrepancies are believed to be caused by an underestimation of ore particle diameter due to an absence of exact measurement data of particle diameter in the region. There exist a thermal reserve zone at temperature between 900 and $1000^{\circ} \mathrm{C}$. On the whole, the measured temperature distribution coincides with the calculated result. However, the calculated temperature in the lower part is relatively high, because heat loss to raise the temperature of liquid phase is not considered. Temperature of solid which enter the raceway is higher than $2000^{\circ} \mathrm{C}$, and temperature of deadman is about $1800-2100^{\circ} \mathrm{C}$.

Figure 10(a) shows the contour of the mass velocity of gas. Figure 10(b) shows pressure distribution and velocity vector of gas. In the stack zone, zigzag patterns of gas flow appear due to the different permeability of the ore and coke layers. ${ }^{19)}$ In the cohesive zone, gas flows preferentially through coke layers due to melting and agglomeration of ore particles, which decreases permeability of ore layers. Therefore, gas velocity increases and gas pressure drop will rise. Figure 10(c) shows streamline of gas through the cohesive zone. We can see gas flows through the coke slit in the cohesive zone, and cohesive layers play a role as gas distributor. Figure 11 shows solid mass velocity contour and solid streamline. Solid velocity decreases with descent and below the cohesive zone, it is further decreased due to melting of ores in the cohesive zone.

Figure 12 shows reduction degree of iron ore such as hematite to magnetite, magnetite to wustite, wustite to iron and overall. Figure 12(a) shows that hematite is converted to magnetite very quickly in the upper part as verified by the experimental observations reported in previous study, ${ }^{20)}$ reactions of magnetite to wustite and wustite to iron would progress sequentially.

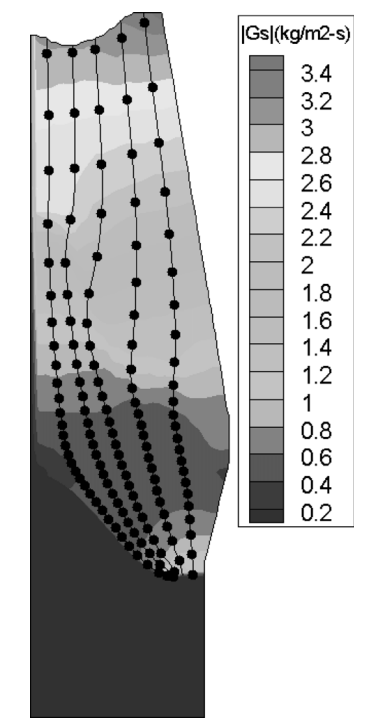

Fig. 11. Calculated results: contour of solid mass velocity $\left(\mathrm{kg} / \mathrm{m}^{2} \cdot \mathrm{s}\right)$ and streamline of solid.

Figure 13 shows mole fraction of $\mathrm{CO}$ and $\mathrm{CO}_{2}$ gases in the gas phase. After combustion in the raceway, reducing gas contains $42.9 \% \mathrm{CO}, 10.9 \% \mathrm{H}_{2}$ and $46.2 \% \mathrm{~N}_{2}$ as presented in Table 4. Molar fraction of $\mathrm{CO}$ gas around the cohesive zone increases due to solution loss reaction and direct reduction. As reduction reactions proceed, concentrations of $\mathrm{CO}_{2}, \mathrm{H}_{2} \mathrm{O}$ increase gradually as the gas ascends through packed bed. Gas composition and $\mathrm{CO}$ gas utilization (\%) at the top of the furnace are shown in Fig. 14. Top gas contains $27.85 \% \mathrm{CO}, 24.69 \% \mathrm{CO}_{2}$ and $5.67 \% \mathrm{H}_{2}$ in calculation data. Therefore, overall $\mathrm{CO}$ gas utilization (\%) is $47.0 \%$. Radial distribution of $\mathrm{CO}$ gas utilization is reversely proportional to the $L_{\mathrm{o}} / L_{\mathrm{c}}$ data because more $\mathrm{CO}$ gas is converted to $\mathrm{CO}_{2}$ in the region where more ore is charged.

Figure 15 shows the longitudinal distribution of reduction degree and gas composition at the dimensionless radial positions of $r / R=0.67$. In Figs. 15(a) and 15(b), there exists the stagnation of magnetite-to-wustite reduction. This stagnation of magnetite-to-wustite reduction is not caused by chemical equilibrium, but rate constant of magnetite- 


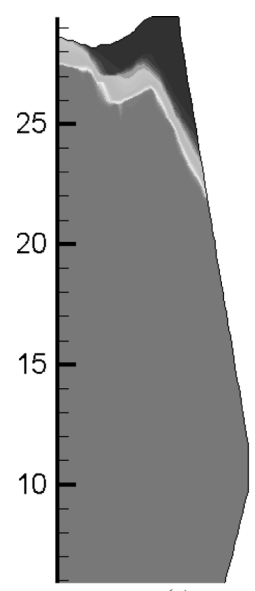

(a)

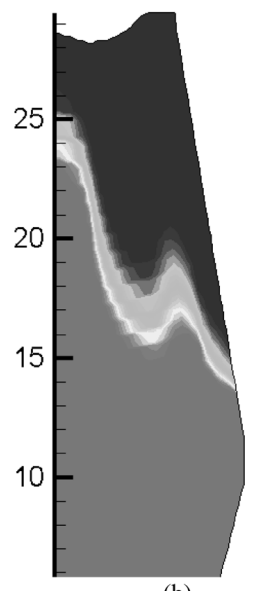

(b)

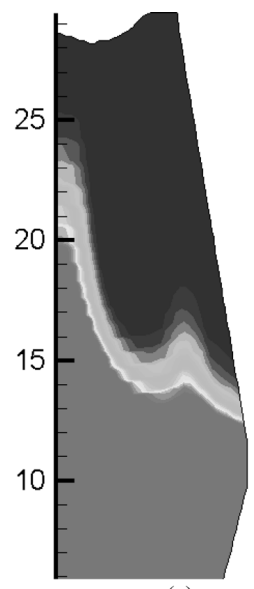

(c)

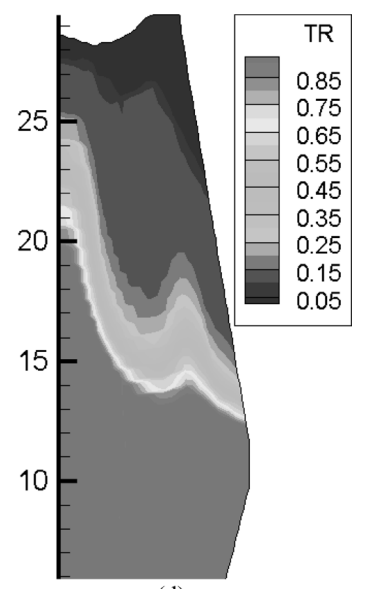

(d)

Fig. 12. Reduction degree of iron ore: (a) hematite to magnetite, (b) magnetite to wustite, (c) wustite to iron and (d) overall.
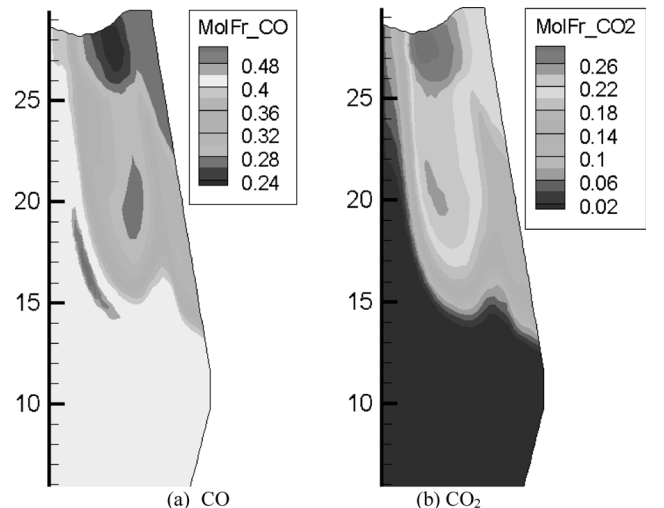

Fig. 13. Mole fraction of (a) $\mathrm{CO}$ and (b) $\mathrm{CO}_{2}$ gas.

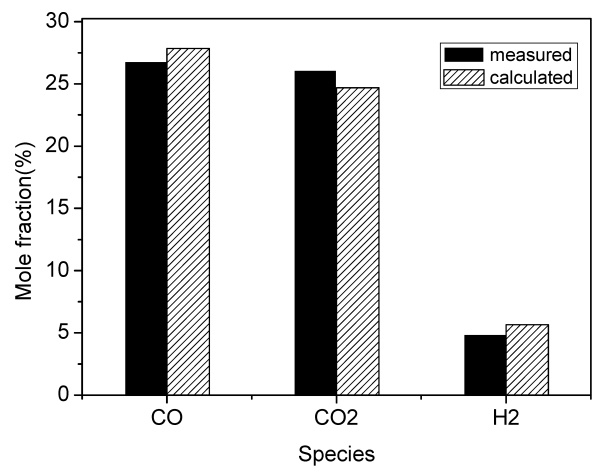

(a)

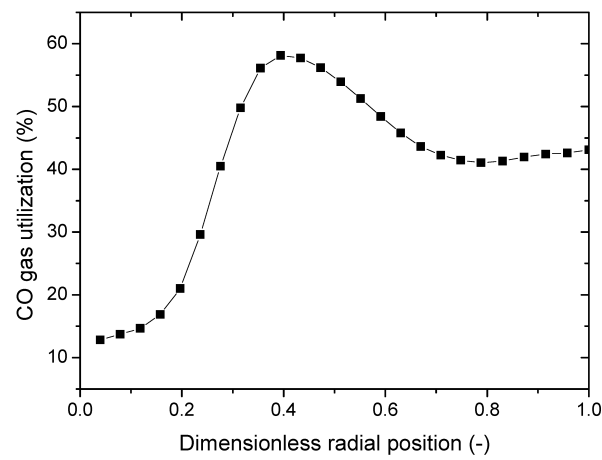

(b)

Fig. 14. (a) Gas composition and (b) CO gas utilization at the top of blast furnace.

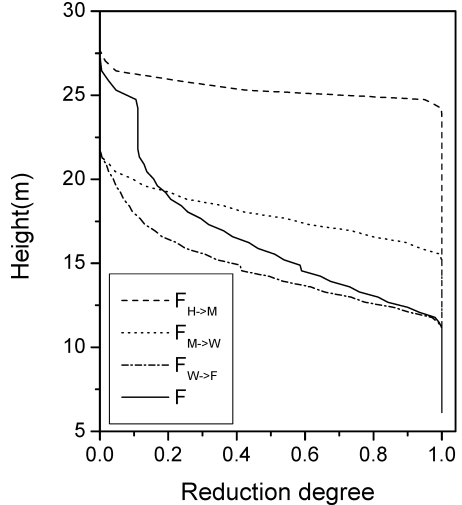

(a)

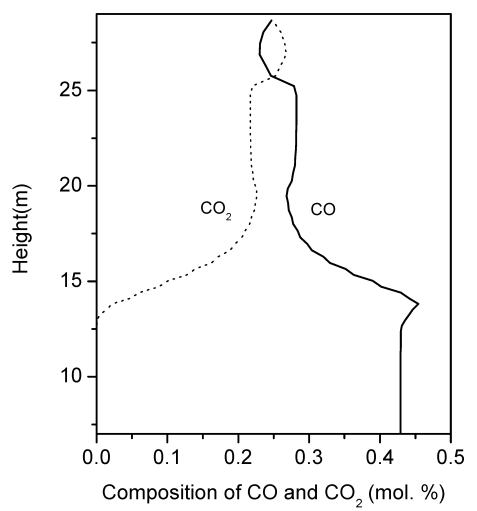

(b)

Fig. 15. Longitudinal distribution at $r / R=0.67$ of (a) reduction degree and (b) gas composition.

to-wustite reduction, determined by temperature. Because magnetite-to-wustite reduction is occurred in too high temperature, the following reduction, wustite-to-metal, is not stagnate, but rapid. Calculated wall gas pressure is compared with measured one as shown in Fig. 16. Most of pressure drop appears in the cohesive zone. Simulation results show a reasonable trend compared with practical operation data.

\section{Conclusion}

Blast furnace process is modelled applying the approach 


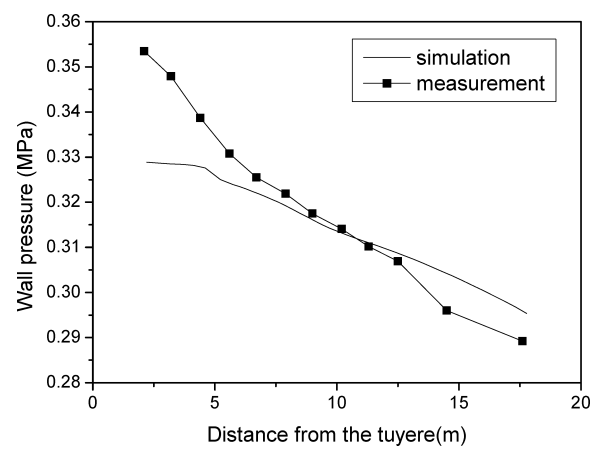

Fig. 16. Gas pressure at the furnace wall.

of the combustion modelling of a solid fuel bed. Layer structure of iron ore and coke packed bed inside the furnace is described in a 2-dimensional axi-symmetric model, and the state of solid and gas phases in the packed bed are represented by a generalized transport equation on mass, momentum and energy. Physico-chemical processes are formulated in a unified model, so that the multi-component flows of solid and gas are represented in a unified manner. As the results, systematic analysis of the blast furnace process, i.e. model derivation and numerical simulation, has been conducted. This generalized computational approach reduces the load in the formulation and numerical processing.

Although the blast furnace model is derived based on physical and chemical changes of the complex ingredients in the furnace, the modelling inevitably employs many submodels like gas-solid interaction, fluid flow, heat transfer, chemical reactions including reduction of iron oxide into iron, change of materials shape and phase transformation etc. As a result, model prediction is strongly dependent on the appropriateness of the sub-models. The model derived has been validated with favourable comparison between calculated and observed solid temperature distribution.

Simulation results for the selected cases are presented on the distribution of temperature, velocity of gas, solid streamline, reduction degree of iron oxide, mole fraction of gas species and pressure. Distributions of solid temperature and gas flow are discussed along with the location and size of cohesive zones. Concentration distribution of gaseous species is interpreted in terms of local reduction degree of iron ore.

\section{Acknowledgement}

The authors would like to express their thanks to POSCO and BK21 (Brain Korea 21) for their financial supports.

\section{Nomenclature}

$\begin{aligned} A: & \text { Specific surface area }\left(\mathrm{m}^{2} / \mathrm{m}^{3}\right) \\ C_{p}: & \text { Specific heat }(\mathrm{kJ} / \mathrm{kg} \cdot \mathrm{K}) \\ d_{p}: & \text { Particle diameter }(\mathrm{m}) \\ F: & \text { Reduction degree }(-) \\ G: & \text { Mass flow rate }\left(\mathrm{kg} / \mathrm{m}^{2} \cdot \mathrm{s}\right) \\ h: & \text { Heat transfer coefficient }\left(\mathrm{kW} / \mathrm{m}^{2} \cdot \mathrm{K}\right) \\ H: & \text { Enthalpy }(\mathrm{kJ} / \mathrm{kg}) \\ H_{f, 298 \mathrm{~K}}^{\circ}: & \text { Enthalpy of formation }(\mathrm{kJ} / \mathrm{kg})\end{aligned}$

$k$ : Conductivity $(\mathrm{kW} / \mathrm{m} \cdot \mathrm{K})$, reaction number

$P$ : $\quad$ Pressure $(\mathrm{Pa})$

Pr: Prandtl number $(-)$

Re : Reynolds number $(-)$

$r$ : Radial coordinate $(\mathrm{m})$

$R:$ Reaction rate $\left(\mathrm{kmol} / \mathrm{m}^{3} \cdot \mathrm{s}\right)$

$r / R:$ Dimensionless radial position (-)

$S$ : Source term in the governing equation

$T$ : Temperature $\left({ }^{\circ} \mathrm{C}\right)$

TR: Reduction degree (-)

$T_{F}$ : Adiabatic flame temperature $(\mathrm{K})$

$v$ : Solid velocity $(\mathrm{m} / \mathrm{s})$

$X$ : mole fraction $(-)$

Greeks

$\varepsilon:$ Porosity $(-)$

$\Gamma:$ Diffusion coefficient

$\mu: \quad$ Viscosity $\left(\mathrm{N} \cdot \mathrm{s} / \mathrm{m}^{2}\right)$

$\rho:$ Density $\left(\mathrm{kg} / \mathrm{m}^{3}\right)$

$\phi$ : Shape factor (-), dependent variable

$\psi$ : Solid velocity potential, stream function

$\omega:$ Mass fraction $(-)$

$v$ : Stoichiometric coefficient

Subscripts

g: Gas phase

$i$ : Component of gas

$j$ : Component of solid

$p$ : Particle

$s$ : Solid phase

gs : Between gas and solid

\section{REFERENCES}

1) P. R. Austin, H. Nogami and J. Yagi: ISIJ Int., 37 (1997), 458.

2) P. R. Austin, H. Nogami and J. Yagi: ISIJ Int., 37 (1997), 748.

3) P. R. Austin, H. Nogami and J. Yagi: ISIJ Int., 38 (1998), 10.

4) J. A. Castro, H. Nogami and J. Yagi: ISIJ Int., 42 (2002), 44.

5) T. Sugiyama and M. Sugata: Seitetsu Kenkyu, (1987), No. 325, 34.

6) K. Takatani, T. Inada and Y. Ujisawa: ISIJ Int., 39 (1999), 15.

7) J. Chen, T. Akiyama, H. Nogami, J. Yagi and H. Takahashi: ISIJ Int., 33 (1993), 664.

8) K. O. Yu and P. P. Gillis: Metall. Mater. Trans. B, 12 (1981), 111.

9) J. G. Peacy and W. G. Davenport: The Iron Blast Furnace-Theory and Practice, Pergamon Press, (1979), 205.

10) W. E. Ranz and W. R. Marshall: Chem. Eng., Prog., 48 (1952), 141.

11) Y. Hara, M. Tsuchiya and S. Kondo: Tetsu-to-Hagané, 55 (1969), 1297.

12) Y. Hara, M. Tsuchiya and S. Kondo: Tetsu-to-Hagané, 60 (1974), 1261.

13) S. Kobayashi and Y. Omori: Tetsu-to-Hagané, 62 (1976), 1081.

14) R. H. Perry, D. W. Green and J. O. Maloney: Perry's Chemical Engineers' Handbook, 7th ed., McGraw-Hill, (1997), 2.

15) R. B. Bird, W. E. Stewart and E. N. Lightfoot: Transport Phenomena, 2nd ed., Wiley Int., New York, (2001), 525.

16) S. V. Patankar: Numerical Heat Transfer and Fluid Flow, McGrawHill, New York, (1984), 44, 52.

17) J. H. Ferziger and M. Peric: Computational Methods for Fluid Dynamics, Springer-Verlag, Berlin, (1997), 219.

18) H. J. Jin: $\mathrm{PhD}$ Thesis, Korea Advanced Institute of Science and Technology, Daejeon, Korea, (2009), 11.

19) M. Kuwabara, E. Chikamatsu and I. Muchi: Tetsu-to-Hagané, 74 (1988), 246.

20) R. Takahashi, Y. Takahashi, J. Yagi and Y. Omori: Trans. Iron Steel Inst. Jpn., 26 (1986), 765. 